\title{
HIGHER ORDER CHEMISTRY MODELS IN THE CFD SIMULATION OF LASER-ABLATED CARBON PLUMES
}

\author{
(An Extended Abstract)
}

\author{
R.B. Greendyke ${ }^{1}$, J.R. Creel ${ }^{2}$, B.T. Payne ${ }^{2}$ \\ Department of Mechanical Engineering \\ The University of Texas at Tyler \\ Tyler, Texas \\ and \\ C.D. $\operatorname{Scott}^{3}$ \\ NASA Johnson Space Center \\ Houston, Texas
}

\begin{abstract}
Production of single-walled carbon nanotubes (SWNT) has taken place for a number of years and by a variety of methods such as laser ablation, chemical vapor deposition, and arc-jet ablation. Yet, little is actually understood about the exact chemical kinetics and processes that occur in SWNT formation. In recent time, NASA Johnson Space Center has devoted a considerable effort to the experimental evaluation of the laser ablation production process for SWNT originally developed at Rice University [1]. To fully understand the nature of the laser ablation process it is necessary to understand the development of the carbon plume dynamics within the laser ablation oven. The present work is a continuation of previous studies [2-5] into the efforts to model plume dynamics using computational fluid dynamics (CFD). The ultimate goal of the work is to improve understanding of the laser ablation process, and through that improved understanding, refine the laser ablation production of SWNT.

Fig. 1 shows a basic schematic of the laser-ablation oven at NASA-JSC. Construction of the facility is simple in concept. Two concentric quartz tubes of $1.5 \mathrm{~mm}$ thickness form the inner and outer tubes with inside diameters of 2.2 and $5.08 \mathrm{~cm}$ respectively. At one end of the inner tube are located two $60 \mathrm{~Hz}$ pulsed lasers operating at $1064 \mathrm{~nm}$ and $532 \mathrm{~nm}$ wavelength with beam diameters of $5 \mathrm{~mm}$ aligned coaxially with the longitudinal axis of the inner quartz tube. For standard nanotube production runs, a 10 ns $532 \mathrm{~nm}$ pulse is followed $50 \mathrm{~ns}$ later by a $10 \mathrm{~ns} 1064 \mathrm{~nm}$ pulse. Each pulse is of 300 $\mathrm{mJ}$ energy. A target of carbon graphite with approximately $1 \%$ nickel and cobalt catalysts [5] is located at the other end of the inner quartz tube.

In the ordinary processing of SWNT, a "base" flow of $100 \mathrm{sccm}$ of argon is maintained from the laser location and exits past the carbon target at a pressure of 66.7 $\mathrm{kPa}$. These conditions yield a baseline mass flow through the chamber of $2.723 \times 10^{-6} \mathrm{~kg} / \mathrm{s}$ of argon. The whole oven facility is heated to a temperature of $1473 \mathrm{~K}$ prior to nanotube
\end{abstract}

\footnotetext{
${ }^{1}$ Assistant Professor, AIAA Associate Fellow

${ }^{2}$ Research Assistant, AIAA Student Member

${ }^{3}$ Research Engineer, AIAA Associate Fellow
} 
production runs. Upon laser irradiation, part of the carbon target ablates immediately and forms a carbon vapor "plume" that penetrates into the argon base flow towards the laser initially at supersonic velocities.

In the previous studies [2-5] either a single carbon species, $\mathrm{C}_{3}$, was used to model the plume development [4-5], or a simplified 11 species carbon model reduced down from the Krestinin and Moravsky model [6] for full fullerene chemistry was used [2-3]. While both of these options yielded significant results, it was felt that the actual chemistry occurring in the carbon plume might have a greater affect on the plume than assumed. Indeed, in the earlier attempts at modeling the carbon plume, several thermophysical characteristics could never be matched to experimental observations of plume development - mainly the propagation distance of the plume itself [7]. In the present study, two additional chemistry models will be used to duplicate the previous studies simulations of the carbon plume.

The first chemistry model used in this study is again a reduced form of the Krestinin and Moravsky rates. However the highest order carbon species allowed has been increased from $\mathrm{C}_{6}$ to $\mathrm{C}_{30}$ - therefore allowing the simulation of up to a "half" of the standard $\mathrm{C}_{60}$ fullerene. The second chemistry model investigated is a "reduced" form of a full carbon nanotube model developed at NASA-JSC. The $\mathrm{C}_{30}$ studies have already been accomplished at the present time, and the "reduced" SWNT model studies are currently underway. To pursue the current study, one sacrifice had to be made in that the simulation grid spacing had to be increased from $0.5 \mathrm{~mm}$ spacing to $1 \mathrm{~mm}$ spacing for the sake of computational efficiency since computational effort is proportional to the square of the number of grid points multiplied by the number of species considered.

Preliminary results of the $\mathrm{C}_{30}$ model have shown a significantly reduced plume propagation that is far more in line with the experimental results observed by Puretzky et al [7] as shown in Fig. 2. The $\mathrm{C}_{6}$ studies had yielded a far greater propagation in previous studies. In addition, chemical species development with the $\mathrm{C}_{30}$ model indicates that many higher order carbon species are produced outside of the plume "proper" (indicated by plotting contours of the background argon concentrations in Fig. 3) - this result was not observed in previous studies. In fact, some species primarily occurred outside of the plume itself - as shown for $\mathrm{C}_{27}$ in Fig. 4 when it is compared to Fig. 3. It could be asserted that this has occurred because all of the $\mathrm{C}_{27}$ in the plume had already been "consumed" in the formation of $\mathrm{C}_{30}$, but this does not seem to be indicated over time.

Several other factors that arose in the previous studies have also been made more clear by the use of the higher order chemical models - one being that the use of $\mathrm{C}_{6}$ as an "indicator species" was mistaken. $\mathrm{C}_{6}$ is the only carbon species in the previous studies that was not "injected" into the flowfield as a boundary condition; it was therefore hoped that this species would provide insight into the formation of higher order carbon species for comparison to full SWNT production. But, when the plot of total mass in the plume is examined on a species by species basis in Fig. 5 , it is seen that $\mathrm{C}_{6}$ was a fairly insignificant contributor to the total carbon mass in the plume and would not provide information on higher order carbon formation.

In the full paper, the authors will examine both the new $\mathrm{C}_{30}$ model results upon the thermophysical characteristics of the carbon plume as well as simulate the carbon plume using the reduced SWNT model to provide an even better simulation of full chemistry effects upon plume propagation. 


\section{References}

1. Guo, T., Nikolaev, P., Thess, A., Colbert, D.T., Smalley, R.E, "Catalytic Growth of Single-Walled Nanotubes by Laser Vaporization," Chemical Physics Letters, Vol. 243, No. 49, 1995.

2. Greendyke, R.B., Swain, J.E., Stein, T.H., Ray, L.A., and Scott, C.D., "Parametric Factors Affecting Carbon Plume Development in SWNT Laser Ablation Production," 42 ${ }^{\text {nd }}$ Aerospace Sciences Meeting, Reno NV, AIAA 2004-0807, January 2004.

3. Greendyke, R.B., Scott, C.D., "CFD Simulation of Laser Ablation Carbon Nanotube Production, ” AIAA 2002-3026, AIAA/ASME $8^{\text {th }}$ Joint

Thermophysics and Heat Transfer Conference, St. Louis, MO, June 2002.

4. Greendyke, R.B. and Scott, C.D., "CFD Analysis of Laser-Ablation Carbon Nanotube Plume Flow Dynamics, ” Annual APS March Meeting 2002, Indianapolis, IN, March 2002.

5. Greendyke, R.B., " CFD Simulation of Carbon Nanotubes," (Hyman, W., Sickorez, D., Miller, M., and Tarkington, W., Editors), NASA Contractor Report on Grants NAG 9-39 and 9-54, Vol. 1, pp. 10-1 to 10-14, Summer 2001.

6. Krestinin, A. V., and Moravsky, A. P., "Mechanisms of Fullerene Synthesis in the Arc Reactor," Chem. Phy. Lett., Vol. 286, pp. 479-484, 1998.

7. Puretzky, A.A., Geohegan, D.B., Fan, X., and Pennycook, S.J., "Dynamics of Single-Wall Carbon Nanotube Synthesis by Laser Vaporization," Applied Physics A, Vol. 70, No. 2, February 2000. 


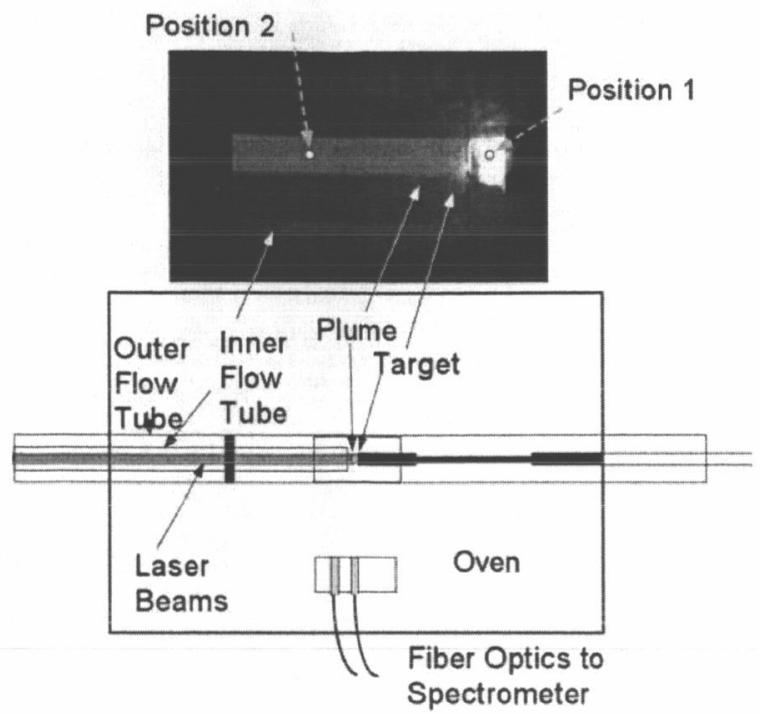

Figure 1 NASA-JSC Laser Ablation Oven Schematic.

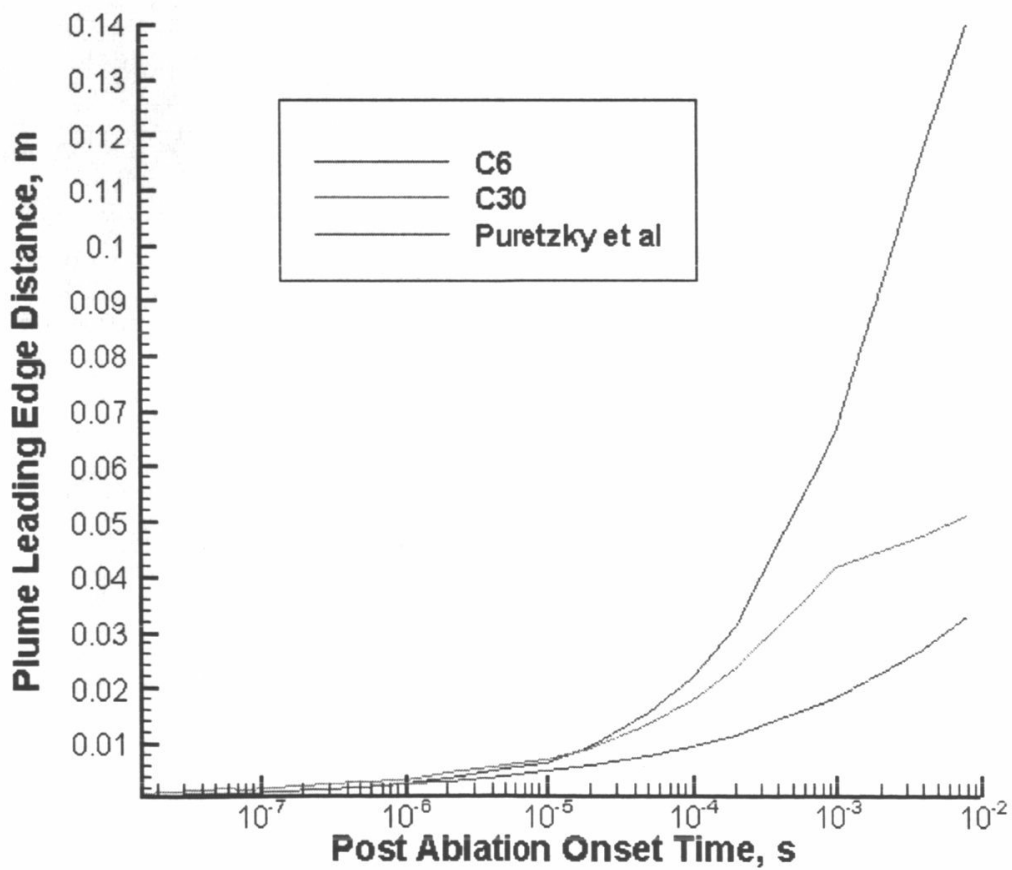

Figure 2 Plume leading edge propagation as a function of time and chemistry model. 


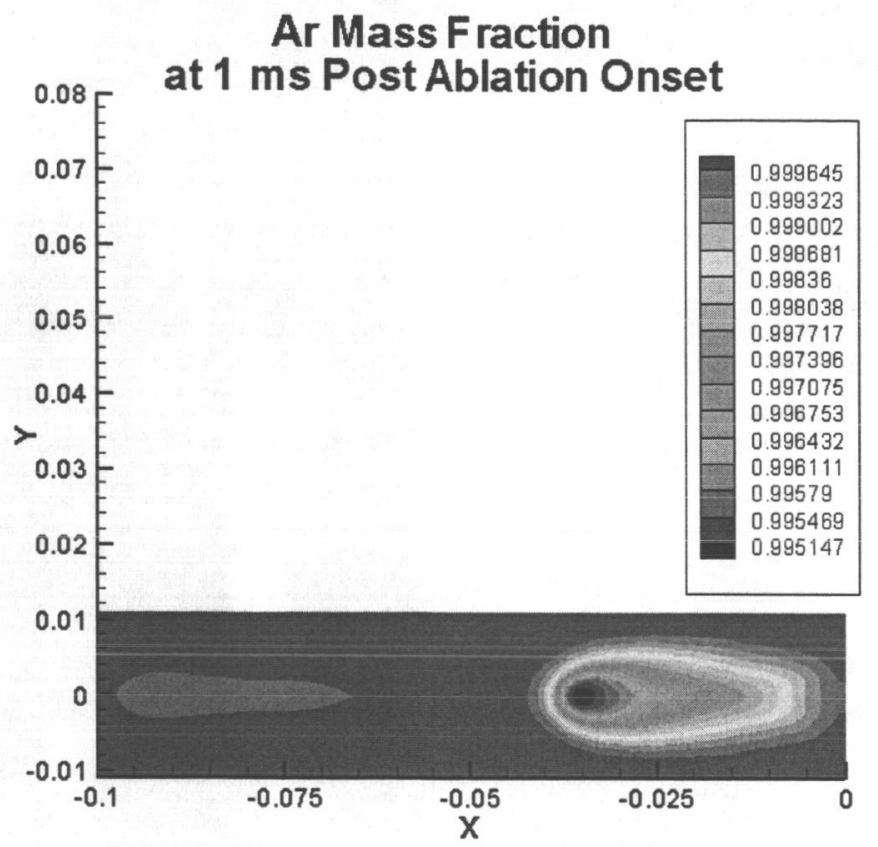

Figure $3 \mathrm{Ar}$ mass fraction contours in the carbon plume at $1 \mathrm{~ms}$ post ablation onset time.

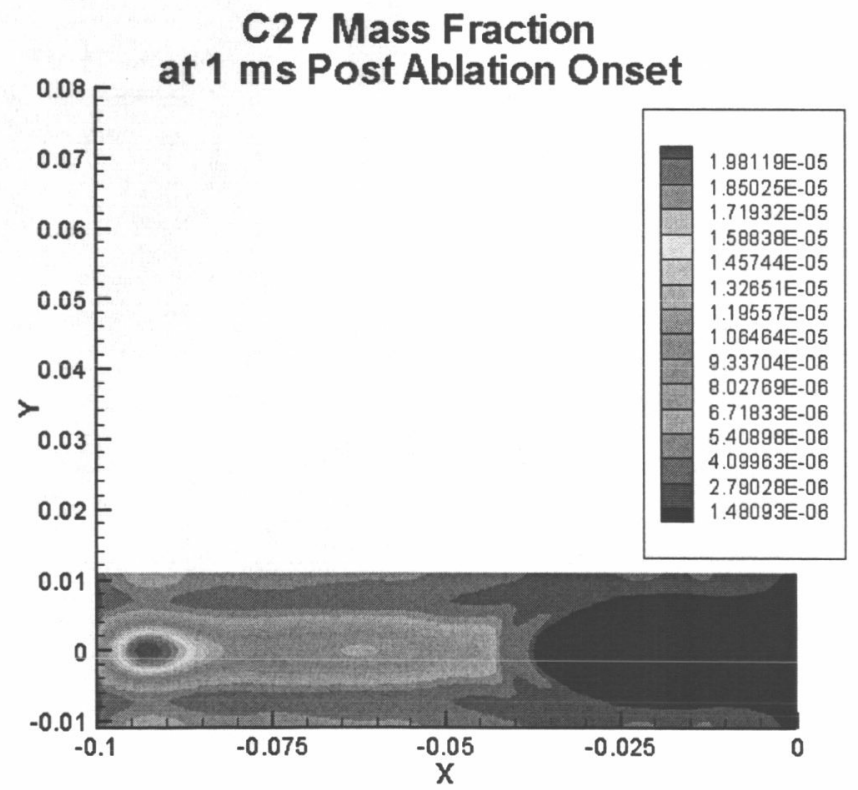

Figure $4 \mathrm{C} 27$ mass fraction contours at $1 \mathrm{~ms}$ post ablation onset time. 


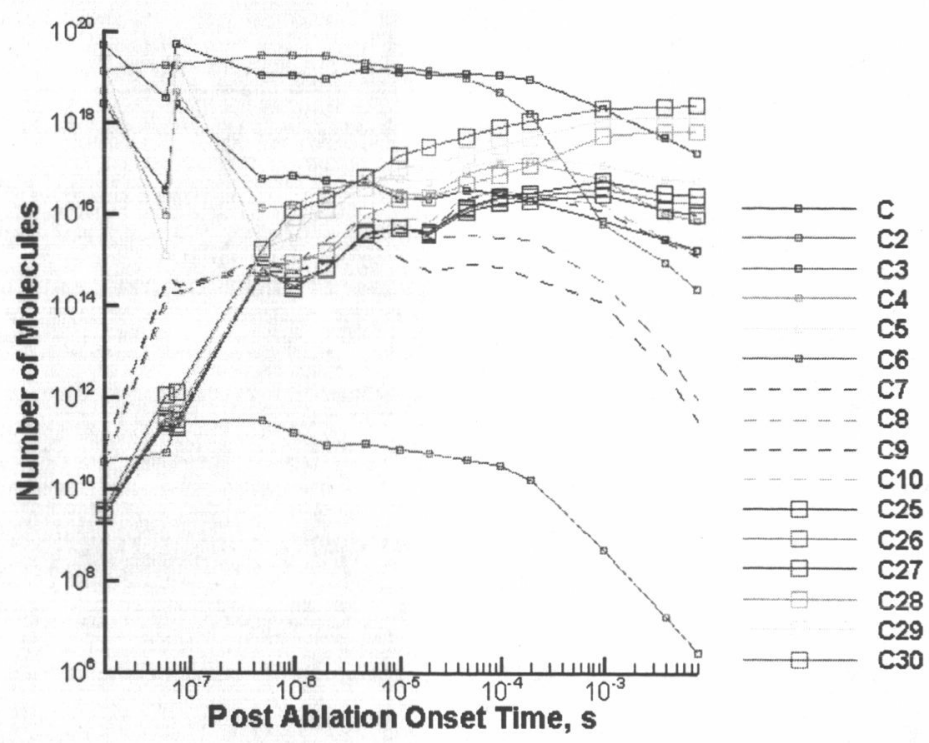

Figure 5 Total masses in the flowfield as a function of post ablation onset time. 